\title{
Hat szabadságfokos robotkarprototípus-modellezés Matlab által
}

\section{Six DOF Robotic Arm Prototype Modelling By Matlab}

\author{
Alaa Saadah, ${ }^{1}$ Husi Géza ${ }^{2}$ \\ Debreceni Egyetem, Müszaki Kar, Mechatronika Tanszék, Debrecen, Magyarország \\ 1 alaa.saadah@eng.unideb.hu \\ ${ }^{2}$ husigeza@eng.unideb.hu
}

\begin{abstract}
The study in this paper allows us to control the manipulator and achieve any desired position and orientation. The Forward Kinematics was done using Denavait Hartenberg (DH) parameters, also the forward kinematics equations and homogenous transformation matrix was validated using MATLAB Toolbox. The modeling was carried out using the Peter Corke robotics toolbox.

Finally, the forward kinematic study and the robot arm's movement equations were compared with practical measurements to make sure it fulfilled the desired purpose and that it could point to the desired coordinates with a precision of $\pm 0.5 \mathrm{~cm}$.
\end{abstract}

Keywords: 6-DOF Industrial manipulator, Forward Kinematics, Peter Corke robotics toolbox.

\section{Összefoglalás}

A tanulmány ebben a cikkben lehetővé teszi számunkra, hogy vezéreljük a manipulátort, és elérjünk minden kívánt helyzetet és orientációt.

A forward kinematics Denavait Hartenberg (DH)-paraméterekkel készült, a forward kinematics-egyenleteket és a homogén transzformációs mátrixot is validálták a MATLAB Toolbox segítségével. A modellezés pedig Peter Corke Robotics toolbox által lett elvégezve.

Végül a forward kinematics-vizsgálat és a robotkar mozgásának egyenletei gyakorlati méréssel lettek kiegészítve, hogy megbizonyosodjunk arról, hogy teljesítik-e a kívánt célt, és $\pm 0,5 \mathrm{~cm}$-es pontossággal mutat a kívánt koordinátákra.

Kulcsszavak: 6-DOF Industrial manipulator, Forward Kinematics, Peter Corke robotics toolbox.

\section{Bevezetés}

A robotkinematika alapvető eszközei a robotot alkotó kinematikai láncok kinematikai egyenletei. Ezeket a nemlineáris egyenleteket arra használják, hogy feltérképezzék a közös paramétereket a robotrendszer konfigurációjához. A kinematikai egyenleteket a csontváz biomechanikájában és a csuklós karakterek számítógépes animációjában is használják.

A forward kinematics egy robot kinematikai egyenleteit használja a end-effector helyzetének kiszámításához az együttes paraméterek megha- tározott értékeiből. Mivel ebben a 21. században nagy a kereslet a kiváló minőségű és nagy pontosságú termékekre az ügyfelek által, ezért számos iparág manapság a robotkar futószalagra való telepítésére és a gyorsabb termelésre fordította a figyelmét.

A robotrendszer egyik legnagyobb kihívást jelentő problémája a kinematikai vizsgálat, különösen az inverz kinematika, amely az adott robotkonfigurációk közös szögeinek megtalálásával foglalkozik.

Az ipari robot manipulátora egy sor kötésből és kapcsolatból áll, az ABB IRB 4400 manipulátor 
prototípusa a manipulátor fizikai felépítésének különböző kötéseinek és kapcsolatainak tanulmányozásával foglalkozik.

\section{Forward Kinematics}

A forward kinematics-probléma a robotmanipulátor egyes ízületei és a szerszám vagy end-effector helyzete és tájolása közötti kapcsolattal foglalkozik [1].

\subsection{Kapcsolatok és ízületek}

Formálisabban fogalmazva, a forward kinematics problémája a end-effektor helyzetének és tájolásának meghatározása, figyelembe véve a robot ízületi változóinak értékeit. Az ízületi változók a kapcsolatok közötti szögek prizmás vagy csúszó esetben [2].

A forward kinematics meghatározza a közös paramétereket, és kiszámítja a lánc konfigurációját. Soros manipulátorok esetében ez úgy érhető el, hogy az ízületi paramétereket közvetlenül a soros lánc forward kinematics egyenleteibe helyettesítik.

A robotmechanizmusok széles skálája írható le az ízületek és az ízületi típusok elrendezésének kategorizálásával. Jelenleg figyelmen kívül hagyjuk a kapcsolatok méretét és alakját, és egyszerüen a széles kategorizálásra összpontosítunk [3].

Először is, három tipikus közös típus létezik, amelyek mindegyike leírja a relatív transzformációk formáját a két kapcsolat között, amelyhez kapcsolódik:

- Revolute: a csatolt kapcsolatok egy közös tengely körül forognak;

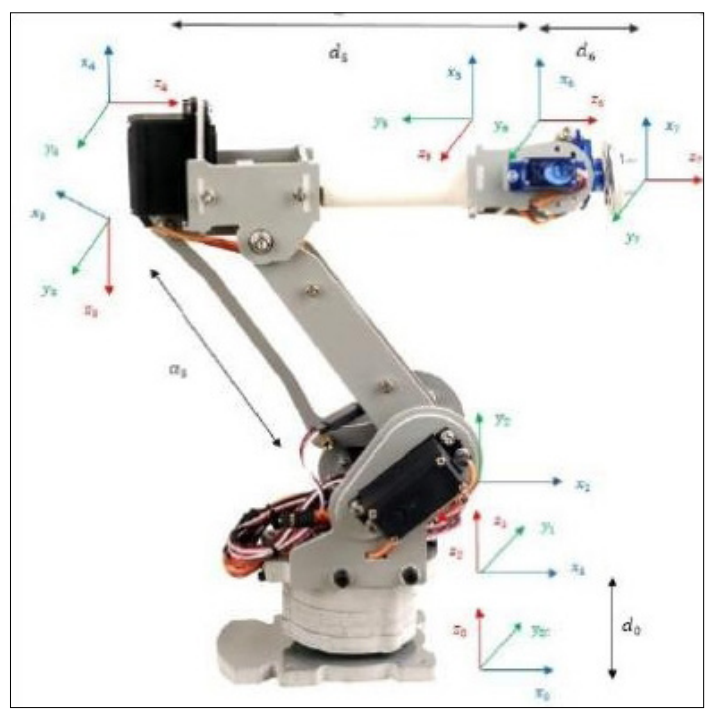

1. ábra. Robotkarkeret hozzárendelése
-Prismatic: a csatolt kapcsolatok egy közös tengely körül mozognak;

-Spherical: a csatolt kapcsolatok egy pont körül forognak.

Az $n$ csuklóval rendelkező robotkar $n+1$ kapcsolattal rendelkezik, mivel minden egyes ízület két kapcsolatot kapcsol össze. Az ízületeket 1-től $n$-ig, a kapcsolatokat 0 -tól $n$-ig számozzuk az alaptól kezdve.

Eszerint, “joint i connects link $i$-1 to link i moves”. Tehát, kapcsolat 0 - az első kapcsolat rögzített és nem mozog, ha az ízületet müködtetik.

\subsection{Denavait Hartenberg}

Négy elsődleges transzformációtól függően kaphatjuk meg a $T_{i}$-t:

$T_{i}=\operatorname{Rot}\left(z, \theta_{i}\right) \operatorname{Trans}\left(z, d_{i}\right) \operatorname{Trans}\left(x, a_{i}\right) \operatorname{Rot}\left(x, a_{i}\right)$

Tehát átvihetjük az $i$ frame-ről az $i+1$ frame-re.

$-\operatorname{Rot}\left(x, \alpha_{i}\right)$ : Forgatás $x$ tengely körül $\alpha_{i}$ szöggel.

- Trans $\left(x, a_{i}\right)$ : Transzformáció $x$ tengelyen $a_{i}$ szöggel.

$-\operatorname{Rot}\left(z, \theta_{i}\right)$ : Forgatás $z$ tengely körül $\theta_{i}$ szöggel.

- Trans $\left(z, d_{i}\right)$ : Transzformáció $z$ tengelyen $d_{i}$ szöggel.

A $T_{i}$ végső mátrix ezeknek a mátrixoknak a többszöröse lesz. [3]

$T_{i}=\left[\begin{array}{llll}c_{\theta i} & -s_{\theta i} & 0 & 0 \\ s_{\theta i} & c_{\theta i} & 0 & 0 \\ 0 & 0 & 1 & 0 \\ 0 & 0 & 0 & 1\end{array}\right] \cdot\left[\begin{array}{cccc}1 & 0 & 0 & 0 \\ 0 & 1 & 0 & 0 \\ 0 & 0 & 1 & d_{i} \\ 0 & 0 & 0 & 1\end{array}\right] \cdot\left[\begin{array}{cccc}1 & 0 & 0 & a_{i} \\ 0 & 1 & 0 & 0 \\ 0 & 0 & 1 & 0 \\ 0 & 0 & 0 & 1\end{array}\right] \cdot\left[\begin{array}{cccc}1 & 0 & 0 & 0 \\ 0 & c_{\alpha i} & -s_{\alpha i} & 0 \\ 0 & s_{\alpha i} & c_{\alpha i} & 0 \\ 0 & 0 & 0 & 1\end{array}\right]$

$T_{i}=\left[\begin{array}{cccc}c_{\theta i} & -s_{\theta i} c_{\alpha i} & s_{\theta i} s_{\alpha i} & a_{i} c_{\theta i} \\ s_{\theta i} & c_{\theta i} c_{\alpha i} & -c_{\theta i} s_{\alpha i} & a_{i} s_{\alpha i} \\ 0 & s_{\alpha i} & c_{\alpha i} & d_{i} \\ 0 & 0 & 0 & 1\end{array}\right]$

$\alpha_{i}, \theta_{i}, d_{i}, a_{i}$

ahol,

$-a_{i}$ : A távolság $z_{i}$ és $z_{i+1}$ között a $x_{i}$ tengelyen.

$-\alpha_{i}$ : A szög $z_{i}$ és $z_{i+1}$ között a $x_{i}$ tengely körül.

$-d_{i}$ : A távolság $x_{i}$ és $x_{i+1}$ között a $z_{i}$ tengelyen.

- $\theta_{i}$ : A szög $x_{i}$ és $x_{i+1}$ között a $z_{i}$ tengely körül.

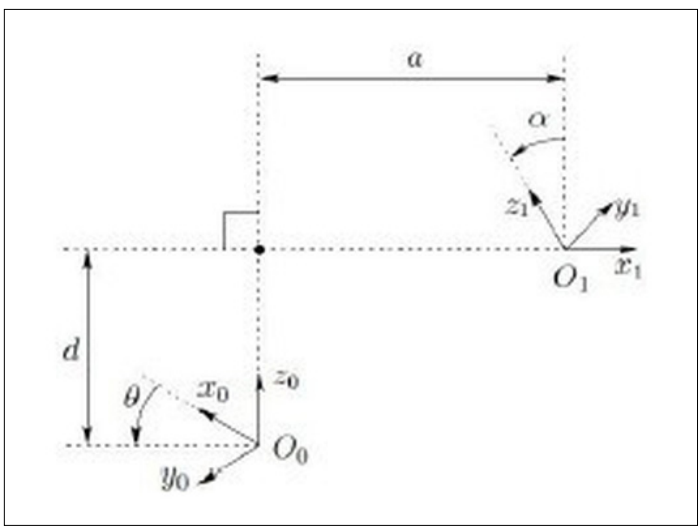

2. ábra. DH-keret hozzárendelése [1] 


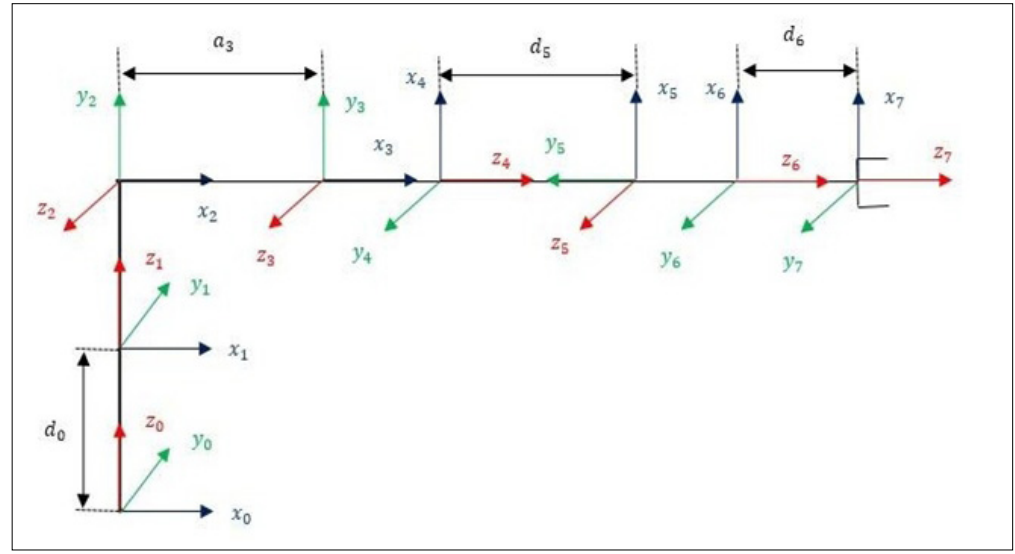

3. ábra. A robotkar koordinátakeretei

\subsection{A robotkar DH-paraméterei}

1. táblázat. Denavait Hartenberg-paraméterek [5].

\begin{tabular}{|c|c|c|c|c|}
\hline $\boldsymbol{i}$ & $\boldsymbol{\theta}_{\boldsymbol{i}-\mathbf{1}}$ & $\boldsymbol{d}_{\boldsymbol{i}-\mathbf{1}}$ & $\boldsymbol{a}_{\boldsymbol{i}}$ & $\boldsymbol{a}_{\boldsymbol{i}}$ \\
\hline 1 & 0 & $d_{0}$ & 0 & 0 \\
\hline 2 & $q_{1}$ & 0 & 0 & $90^{\circ}$ \\
\hline 3 & $q_{2}$ & 0 & $a_{3}$ & 0 \\
\hline 4 & $90^{\circ}+q_{3}$ & 0 & 0 & $90^{\circ}$ \\
\hline 5 & $q_{4}$ & $d_{4}$ & 0 & $-90^{\circ}$ \\
\hline 6 & $q_{5}$ & 0 & 0 & $90^{\circ}$ \\
\hline 7 & $q 6$ & $d_{6}$ & 0 & 0 \\
\hline
\end{tabular}

$T_{1}^{0}=\left[\begin{array}{cccc}1 & 0 & 0 & 0 \\ 0 & 1 & 0 & 0 \\ 0 & 0 & 1 & d_{0} \\ 0 & 0 & 0 & 1\end{array}\right]$

$T_{2}^{1}=\left[\begin{array}{cccc}c_{q_{1}} & 0 & s_{q_{1}} & 0 \\ s_{q_{1}} & 0 & -c_{q_{1}} & 0 \\ 0 & 1 & 0 & 0 \\ 0 & 0 & 0 & 1\end{array}\right]$

$T_{3}^{2}=\left[\begin{array}{cccc}c_{q_{2}} & -s_{q_{2}} & 0 & c_{q_{2}} a_{3} \\ s_{q_{2}} & c_{q_{2}} & 0 & s_{q_{2}} a_{3} \\ 0 & 0 & 1 & 0 \\ 0 & 0 & 0 & 1\end{array}\right]$

$T_{4}^{3}=\left[\begin{array}{cccc}-s_{q_{3}} & 0 & c_{q_{3}} & 0 \\ c_{q_{3}} & 0 & s_{q_{3}} & 0 \\ 0 & 1 & 0 & 0 \\ 0 & 0 & 0 & 1\end{array}\right]$

$T_{5}^{4}=\left[\begin{array}{cccc}c_{q_{4}} & 0 & -s_{q_{4}} & 0 \\ s_{q_{4}} & 0 & c_{q_{4}} & 0 \\ 0 & -1 & 0 & d_{5} \\ 0 & 0 & 0 & 1\end{array}\right]$

$T_{6}^{5}=\left[\begin{array}{cccc}c_{q_{5}} & 0 & s_{q_{5}} & 0 \\ s_{q_{5}} & 0 & -c_{q_{5}} & 0 \\ 0 & 1 & 0 & 0 \\ 0 & 0 & 0 & 1\end{array}\right]$

$$
T_{7}^{6}=\left[\begin{array}{cccc}
c_{q_{6}} & -s_{q_{6}} & 0 & 0 \\
s_{q_{6}} & c_{q_{6}} & 0 & 0 \\
0 & 0 & 1 & d_{6} \\
0 & 0 & 0 & 1
\end{array}\right]
$$

$$
T_{7}^{0}=T_{1}^{0} \cdot T_{2}^{1} \cdot T_{3}^{2} \cdot T_{4}^{3} \cdot T_{5}^{4} \cdot T_{6}^{5} \cdot T_{7}^{6}=\left[\begin{array}{cccc}
\mu_{x} & o_{x} & \alpha_{x} & p_{x} \\
\mu_{y} & O_{y} & \alpha_{y} & p_{y} \\
\mu_{z} & o_{z} & \alpha_{z} & p_{z} \\
0 & 0 & 0 & 1
\end{array}\right]
$$

$$
\begin{aligned}
\mu_{x}= & -c_{q_{1}} c_{q_{2}} s_{q_{3}} c_{q_{4}} c_{q_{5}} c_{q_{6}}+c_{q_{1}} c_{q_{2}} s_{q_{3}} s_{q_{4}} s_{q_{6}} \\
& -c_{q_{1}} c_{q_{2}} c_{q_{3}} s_{q_{5}} c_{q_{6}}-c_{q_{1}} s_{q_{2}} c_{q_{3}} c_{q_{4}} c_{q_{5}} c_{q_{6}} \\
& +c_{q_{1}} s_{q_{2}} c_{q_{3}} s_{q_{4}} s_{q_{6}}+c_{q_{1}} s_{q_{2}} s_{q_{3}} s_{q_{5}} c_{q_{6}} \\
& +s_{q_{1}} s_{q_{4}} c_{q_{5}} c_{q_{6}}+s_{q_{1}} c_{q_{4}} s_{q_{6}}
\end{aligned}
$$

$$
\begin{aligned}
\mu_{y}= & -s_{q_{1}} c_{q_{2}} s_{q_{3}} c_{q_{4}} c_{q_{5}} c_{q_{6}}+s_{q_{1}} c_{q_{2}} s_{q_{3}} s_{q_{4}} s_{q_{6}} \\
& -s_{q_{1}} c_{q_{2}} c_{q_{3}} s_{q_{5}} c_{q_{6}}-s_{q_{1}} s_{q_{2}} c_{q_{3}} c_{q_{4}} c_{q_{5}} c_{q_{6}} \\
& +s_{q_{1}} s_{q_{2}} c_{q_{3}} s_{q_{4}} s_{q_{6}}+s_{q_{1}} s_{q_{2}} s_{q_{3}} s_{q_{5}} c_{q_{6}} \\
& -c_{q_{1}} s_{q_{4}} c_{q_{5}} c_{q_{6}}-c_{q_{1}} c_{q_{4}} s_{q_{6}}
\end{aligned}
$$

$$
\begin{aligned}
\mu_{z}= & -s_{q_{2}} s_{q_{3}} c_{q_{4}} c_{q_{5}} c_{q_{6}}+s_{q_{2}} s_{q_{3}} s_{q_{4}} s_{q_{6}} \\
& -s_{q_{2}} c_{q_{3}} s_{q_{5}} c_{q_{6}}+c_{q_{2}} c_{q_{3}} c_{q_{4}} c_{q_{5}} c_{q_{6}} \\
& -c_{q_{2}} c_{q_{3}} s_{q_{4}} s_{q_{6}}-c_{q_{2}} s_{q_{3}} s_{q_{5}} c_{q_{6}}
\end{aligned}
$$

$$
\begin{aligned}
O_{x}= & c_{q_{1}} c_{q_{2}} s_{q_{3}} c_{q_{5}} s_{q_{6}}+c_{q_{1}} c_{q_{2}} s_{q_{3}} s_{q_{4}} s_{q_{6}} \\
& +c_{q_{1}} c_{q_{2}} c_{q_{3}} s_{q_{5}} s_{q_{6}}+c_{q_{1}} s_{q_{2}} c_{q_{3}} c_{q_{5}} s_{q_{6}} \\
& +c_{q_{1}} s_{q_{2}} c_{q_{3}} s_{q_{4}} s_{q_{6}}-s_{q_{1}} s_{q_{4}} c_{q_{5}} s_{q_{6}} \\
& +s_{q_{1}} c_{q_{4}} c_{q_{6}}
\end{aligned}
$$

$$
\begin{aligned}
O_{y}= & s_{q_{1}} c_{q_{2}} s_{q_{3}} c_{q_{5}} s_{q_{6}}+s_{q_{1}} c_{q_{2}} s_{q_{3}} s_{q_{4}} s_{q_{6}} \\
& +s_{q_{1}} c_{q_{2}} c_{q_{3}} s_{q_{5}} s_{q_{6}}+s_{q_{1}} s_{q_{2}} c_{q_{3}} c_{q_{5}} s_{q_{6}} \\
& +s_{q_{1}} s_{q_{2}} c_{q_{3}} s_{q_{4}} s_{q_{6}}-s_{q_{1}} s_{q_{2}} s_{q_{3}} s_{q_{5}} s_{q_{6}} \\
& +c_{q_{1}} s_{q_{4}} c_{q_{5}} s_{q_{6}}-c_{q_{1}} c_{q_{4}} c_{q_{6}}
\end{aligned}
$$

$$
\begin{aligned}
O_{z}= & s_{q_{2}} s_{q_{3}} c_{q_{5}} s_{q_{6}}+s_{q_{2}} s_{q_{3}} s_{q_{4}} s_{q_{6}} \\
& +s_{q_{2}} c_{q_{3}} s_{q_{5}} s_{q_{6}}-c_{q_{2}} c_{q_{3}} c_{q_{5}} s_{q_{6}} \\
& -c_{q_{2}} c_{q_{3}} s_{q_{4}} s_{q_{6}}+c_{q_{2}} s_{q_{3}} s_{q_{5}} s_{q_{6}}
\end{aligned}
$$




$$
\begin{array}{cc}
a_{x}=-c_{q_{1}} c_{q_{2}} s_{q_{3}} c_{q_{4}} s_{q_{5}}+c_{q_{1}} c_{q_{2}} c_{q_{3}} c_{q_{5}} & \text { 3. A forward kinematics-modell validá- } \\
-c_{q_{1}} s_{q_{2}} c_{q_{3}} c_{q_{4}} s_{q_{5}}-c_{q_{1}} s_{q_{2}} s_{q_{3}} c_{q_{5}} & \text { lása }
\end{array}
$$

\section{A forward kinematics-modell validá- lása}$$
+s_{q_{1}} s_{q_{4}} s_{q_{5}}
$$$$
a_{y}=-s_{q_{1}} c_{q_{2}} s_{q_{3}} c_{q_{4}} s_{q_{5}}+s_{q_{1}} c_{q_{2}} c_{q_{3}} c_{q_{5}}
$$$$
-s_{q_{1}} s_{q_{2}} c_{q_{3}} c_{q_{4}} s_{q_{5}}-s_{q_{1}} s_{q_{2}} s_{q_{3}} c_{q_{5}}
$$$$
-c_{q_{1}} s_{q_{4}} s_{q_{5}}
$$$$
a_{z}=-s_{q_{2}} s_{q_{3}} c_{q_{4}} s_{q_{5}}+s_{q_{2}} c_{q_{3}} c_{q_{5}}
$$$$
+c_{q_{2}} c_{q_{3}} c_{q_{4}} s_{q_{5}}+c_{q_{2}} s_{q_{3}} c_{q_{5}}
$$$$
p_{x}=-c_{q_{1}} c_{q_{2}} s_{q_{3}} c_{q_{4}} s_{q_{5}} d_{6}+c_{q_{1}} c_{q_{2}} c_{q_{3}} c_{q_{5}} d_{6}
$$$$
+c_{q_{1}} c_{q_{2}} c_{q_{3}} d_{4}-c_{q_{1}} s_{q_{2}} c_{q_{3}} c_{q_{4}} s_{q_{5}} d_{6}
$$$$
-c_{q_{1}} s_{q_{2}} s_{q_{3}} c_{q_{5}} d_{6}-c_{q_{1}} s_{q_{2}} s_{q_{3}} d_{4}+c_{q_{1}} c_{q_{2}} a_{3}
$$$$
+s_{q_{1}} s_{q_{4}} s_{q_{5}} d_{6}
$$$$
p_{y}=-s_{q_{1}} c_{q_{2}} s_{q_{3}} c_{q_{4}} s_{q_{5}} d_{6}+s_{q_{1}} c_{q_{2}} c_{q_{3}} c_{q_{5}} d_{6}
$$$$
+s_{q_{1}} c_{q_{2}} c_{q_{3}} d_{4}-s_{q_{1}} s_{q_{2}} c_{q_{3}} c_{q_{4}} s_{q_{5}} d_{6}
$$$$
-s_{q_{1}} s_{q_{2}} s_{q_{3}} c_{q_{5}} d_{6}-s_{q_{1}} s_{q_{2}} s_{q_{3}} d_{4}+s_{q_{1}} c_{q_{2}} a_{3}
$$$$
-c_{q_{1}} s_{q_{4}} s_{q_{5}} d_{6}
$$$$
p_{z}=-s_{q_{2}} s_{q_{3}} c_{q_{4}} s_{q_{5}} d_{6}+s_{q_{2}} c_{q_{3}} c_{q_{5}} d_{6}+s_{q_{2}} c_{q_{3}} d_{4}
$$$$
+c_{q_{2}} c_{q_{3}} c_{q_{4}} s_{q_{5}} d_{6}+c_{q_{2}} s_{q_{3}} c_{q_{5}} d_{6}+c_{q_{2}} s_{q_{3}} d_{4}
$$$$
+s_{q_{2}} a_{3}+d_{0}
$$

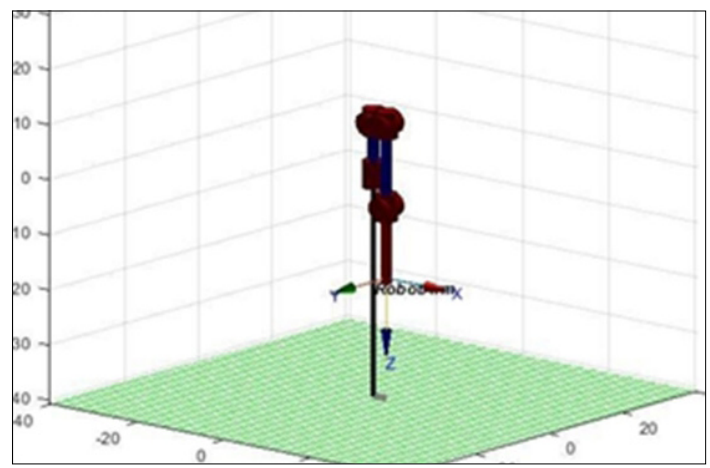

4. ábra. A 2. táblázat 1. esete szerinti ízületi szöget ábrázolja [2]

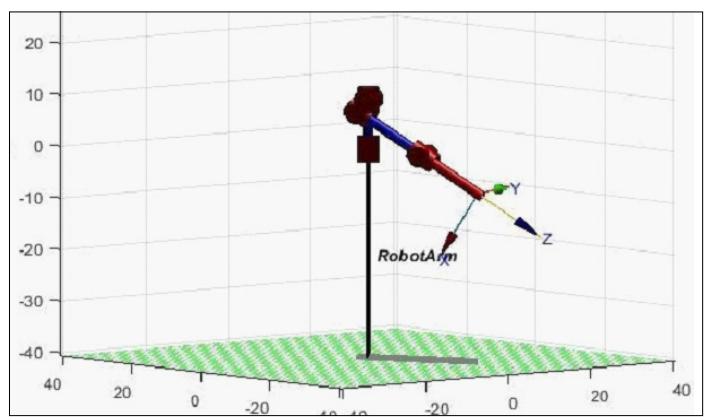

5. ábra. A 2. táblázat 2. esete szerinti ízületi szöget ábrázolja [2]
A forward kinematics- és a homogén transzformációs mátrix a MATLAB-bal ellátott Peter Corke Robotics toolbox segítségével lett validálva [6].

$\mathrm{Az}$ egyenletek értéke és a vizuális ábrázolások, valamint a Matlabban a robotkar végeffektor-helyzete és tájolása egyértelmü betekintést nyújt a robotkar mozgására [7].

Különböző szögeket állítottak be bemenetként, és az eredmény a következő ábrák szerint lett kialakítva és ábrázolva.

2. táblázat. Különféle szögek bemenetként

\begin{tabular}{|c|c|c|c|c|c|c|c|}
\hline Szög & $\boldsymbol{q}_{\mathbf{1}}$ & $\boldsymbol{q}_{\mathbf{2}}$ & $\boldsymbol{q}_{\mathbf{3}}$ & $\boldsymbol{q}_{\mathbf{4}}$ & $\boldsymbol{q}_{\mathbf{5}}$ & $\boldsymbol{q}_{\mathbf{6}}$ & $\boldsymbol{q}_{\mathbf{7}}$ \\
\hline 1 & 0 & 0 & 0 & 0 & 0 & 0 & 0 \\
\hline 2 & 0 & 90 & -45 & 0 & 0 & 0 & 0 \\
\hline 3 & 0 & 45 & 45 & -90 & 45 & 45 & 45 \\
\hline 4 & 0 & 45 & 0 & -90 & 45 & 45 & 45 \\
\hline
\end{tabular}

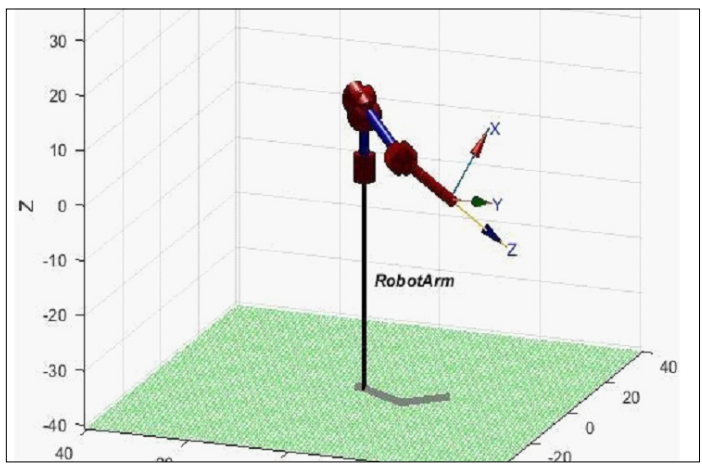

6. ábra. A 2. táblázat 3. esete szerinti ízületi szöget ábrázolja [2]

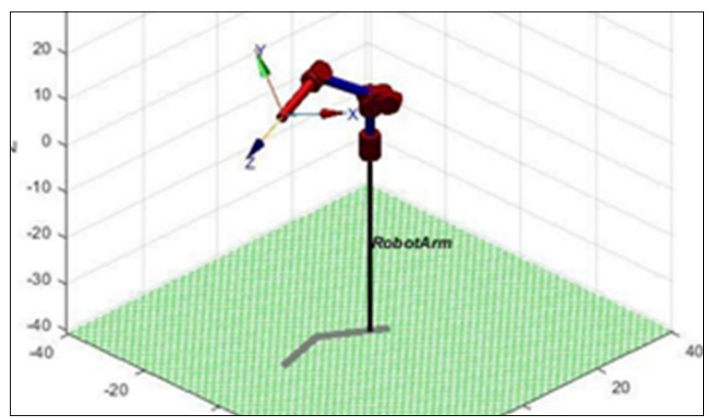

7. ábra. A 2. táblázat 4. esete szerinti ízületi szöget ábrázolja [2] 


\section{4. Összefoglalás}

A forward kinematics-modellt MATLAB-okkal validálták. A forward kinematics-modell eredménye megegyezik a homogén transzformációs mátrix script-eredményével. [9] A modellből kapott pozíciókat összehasonlították a robot tényleges teljesítményével, hogy érzékeljék az end-effector pozícióját és a tájolást. A robot $\pm 0,5 \mathrm{~cm}$-en belül éri el a pozíciópontosságot, ez a kis eltérés több okból is van, például az illesztések mechanikus összekapcsolása és a leképezési szögek nemlinearitása, az alacsony szintü encoder tickig.

\section{Szakirodalmi hivatkozások}

[1] Shrivastava S.: Forward Kinematics of Articulated Robotic Arm. International Journal of Research and Scientific Innovation, IV/VIII. (2017) 78-82.

[2] Iqbal J., Islam R., Khan H.: Modeling and Analysis of a 6 DOF Robotic Arm Manipulator. Canadian Journal on Electrical and Electronics Engineering, 3/6. (2012) 300-306.

[3] Zhang D., Wei B.: A Review on Model Reference Adaptive Control of Robotic Manipulators. Annual Reviews in Control, 43. (2017) 188-198.
[4] Hou Z.: Kinematics Analysis and Self-Collision Detection of Truss Type Multi-Robot. In: $52^{\text {nd }}$ CIRP Conference on Manufacturing Systems, Shanghai, China, 2019.

[5] Saadah A., Husi G.: Computing The Kinematics Study of a 6 DOF Industrial Manipulator Prototype By Matlab. Recent Innovations in Mechatronics, 7/1. (2020) 1-5. https://doi.org/10.17667/riim.2020.1/8.

[6] Corke P.: Robotics, Vision and Control. Fundamental Algorithms In MATLAB® Second, Completely Revised, Extended And Updated Edition. Springer, 2017.

[7] Krishnan M. G.: Kinematic Analysis and Validation of an Industrial. In: IEEE TENCON Conference, Kerala, 2019.

[8] Liu F.: Kinematic Analysis and Simulation of a 3-DOF robotic. In: IEEE International Conference on Computational Intelligence and Communication Technology, Ghaziabad, 2017.

[9] MATLAB 2018a, The MathWorks, Inc., Natick, Massachusetts, United States. 